DOI: http://dx.doi.org/10.18309/anp.v1i48.1217

\title{
DISCURSOS SOBRE A FALA PÚBLICA POPULAR NA IMPRENSA BRASILEIRA
}

\section{DISCOURSES ABOUT POPULAR PUBLIC SPEAKING IN THE BRAZILIAN PRESS}

Carlos Piovezani

Universidade Federal de São Carlos/CNPq, São Carlos, São Paulo, Brasil

Resumo: Com base nos postulados teóricos e nos procedimentos metodológicos da Análise do discurso, o artigo analisa as primeiras edições do jornal anarquista A Plebe, publicadas no Brasil, em 1917. O objetivo da análise consiste em descrever e interpretar uma série de enunciados extraídos de textos publicados nessas edições de A Plebe, com vistas a identificar discursos sobre as práticas de fala pública popular provenientes de posições ideológicas progressistas. Mais precisamente, a abordagem discursiva desses textos permite mais bem compreender o que dizem os enunciadores anarquistas sobre a oratória popular, em condições históricas de efervescência do movimento operário. Além disso, este estudo possibilita uma maior compreensão de aspectos e fenômenos da formulação linguística dos enunciados em que as falas públicas populares são tematizadas.

Palavras-chave: Análise do Discurso; Fala Pública Popular; Imprensa Brasileira

\begin{abstract}
Based on the theoretical postulates and methodological procedures of Discourse Analysis, the article analyzes the first editions of the anarchist journal A Plebe, published in Brazil, in the year 1917. The purpose of the analysis is to describe and interpret a series of statements extracted from texts published in these issues of A Plebe, with the aim of identifying discourses about the practices of popular public speaking from progressive ideological positions. More precisely, the discursive approach of these texts allows us to better understand what the anarchist enunciators say about popular oratory, under historical conditions of effervescence of the labor movement. In addition, this study allows a better understanding of aspects and phenomena of the linguistic formulation of statements in which popular public speaking are thematized.
\end{abstract}

Keywords: Dicourse Analysis; Popular Public Speaking; Brazilian Press 


\title{
INTRODUÇÃO
}

No dia 09 de junho de 1917, era publicada a primeira edição do jornal A Plebe. Tratava-se de um veículo da imprensa operária, particularmente filiado à linha ideológica anarquista-sindicalista. O periódico se inscreve em uma série que poderia remontar a outros de distintas tendências igualitárias do final do século XIX, tais como A Metralha, O Socialista e A União operária, entre outros ${ }^{1}$. Em seu primeiro editorial, Edgard Leuenroth, seu editor, traça o programa do jornal: "combate a todos os elementos de opressão que sujeitam o povo deste país" (LEUENROTH, 1917, p. 1).

Os papeis a serem desempenhados pelos atores sociais em sua realização estão bem definidos e repetem um esquema já há muito consolidado: à imprensa "avançada", na esteira das "mentes privilegiadas dos mártires da independência, dos heróis da abolição e da cruzada republicana" e ainda da "obra dos abnegados de outrora", "cabe lugar de destaque". Tal imprensa se destaca dos "jornais ao soldo dos dominadores da época" e sua "missão delicada" é a de "orientar o povo" e ainda de lhe dar voz, na medida em que A Plebe se apresenta como "eco permanente das lamentações, dos protestos e do conclamar ameaçador dessa plebe imensa que vive sempiternamente a mourejar, em condições de escravos modernos" (LEUENROTH, 1917, p. 1). O programa é necessário, mas o retrato que ali se faz do povo e das funções que lhe são atribuídas não são exatamente positivos. Além de oprimido, o povo está desorientado, sem voz e à mercê da manipulação dos dominantes.

Seria algo distinto o que então era afirmado pela imprensa anarquista a respeito das competências da fala pública popular? Quais eram, afinal, os discursos sobre a oratória dos sujeitos das classes populares materializados nesse importante veículo da imprensa alternativa brasileira? Haveria neles a reiteração dos preconceitos contra as práticas populares de linguagem que se encontram nas ideologias conservadoras ou, antes, a concessão quase inédita de espaço e legitimidade na história brasileira à voz do povo? Eis algumas das questões fundamentais que pretendemos responder aqui. Para tanto, empreenderemos uma análise discursiva de uma série de enunciados extraídos das duas primeiras edições de $A$ Plebe, publicadas num momento de particular efervescência operária no Brasil.

\section{DISCURSOS PROGRESSISTAS SOBRE A FALA PÚBLICA POPULAR}

Desde sua primeira edição, A Plebe reservará espaço para uma seção, inicialmente, intitulada "Ação obreira". Estavam ali concentradas as notícias e opiniões sobre os movimentos embrionários da greve geral que ocorreria naquele ano em São Paulo². Ainda naquela edição de 09 de junho, podemos ler o seguinte:

\author{
Ação Obreira \\ O operariado de São Paulo parece despertar para a luta \\ Movimentos grevistas - Associações que surgem
}

\begin{abstract}
Se não chegou a conseguir libertar as crianças da escravidão, dos ergástulos do trabalho, porque isso só era feito pela ação direta dos trabalhadores rebelados contra esse hediondo crime da burguesia rapace, serviu, entretanto, a vivaz campanha recentemente realizada pelos libertários para determinar uma certa predisposição no sentido da atividade no seio da classe obreira desta capital.

A propaganda feita em numerosos comícios e em boletins não deixou de produzir o seu efeito, fazendo com que os trabalhadores, sujeitos agora, como nunca, a uma situação verdadeiramente intolerável, devido à ação aladroada dos patrões, insaciáveis sanguessugas sociais, se comece a sentir
\end{abstract}

\footnotetext{
${ }^{1}$ Sobre a imprensa operária no Brasil, ver: Ferreira (1978).

${ }^{2}$ Para mais informações sobre a greve geral de 1917, ver: Lopreato (2000) e Giannotti (2007).
} 
a necessidade de agir contra os bandidos que, ao abrigo da lei, vivem a roubar o produto de seu trabalho insano.

Alguns movimentos grevistas já se manifestaram, ao mesmo tempo que se vai tratando de constituir associações de resistência e de acentuada luta social.

Dando execução ao seu programa, o Comitê Popular de Agitação Contra a Exploração dos Menores Operários tem promovido reuniões em vários bairros com o fim de organizar as ligas operárias que, dentro em breve, reconstituirão a União Geral dos Trabalhadores.

Os trabalhos nesse sentido prosseguem e é de se esperar que, no mais breve tempo possível, o proletariado de S. Paulo possa dispor de uma potente organização de luta para fazer frente com vantagem aos miseráveis que, pavoneando-se estupidamente com títulos e comendas comprados a peso de ouro, vão acumulando fortunas colossais às custas de indefesas crianças, de pobres mulheres, da velhice alquebrada e de uma multidão de homens a quem a miséria contínua do seu triste viver amorteceu a noção da dignidade e da altivez.

Oxalá, pois, que o movimento promissor, agora em início, ganhe o devido vulto tão rapidamente quanto a gravíssima situação o exige. (VILLAR, 1917a, p. 3)

Somos informados da exploração do trabalho infantil, da quase infrutífera ação, se não para eliminá-la, ao menos para atenuá-la, da campanha empreendida para fazê-lo e da existência de programas de propaganda e de organização trabalhista. Tais programas compreendem "numerosos comícios" e "boletins". O tom é o da denúncia indignada, mas é ainda mais o da esperança com o movimento operário, que cada vez mais estaria se coordenando e se rebelando. É essa expectativa que predomina nas notas a respeito dos eventos que estavam, então, ocorrendo em várias regiões da cidade e de seus arredores. Como veremos imediatamente abaixo, em tais notas, há várias referências à propaganda, às reuniões e aos comícios das associações organizadas do proletariado:

\section{Liga Operária da Mooca}

Das agremiações obreiras que estão surgindo esta é a que mais rápido desenvolvimento tem tomado, contribuindo, naturalmente, para isso os dois movimentos que os tecelões venceram em fábricas situadas naquele bairro.

Numerosas reuniões foram realizadas durante e após a greve da fábrica de tecidos Rodolpho Crespi, sendo elas aproveitadas para a propaganda feita por camaradas nossos.

A Liga Operária da Mooca, contando com um bom número de associados, está instalando a sua sede à rua da Mooca, 190, devendo ela ser inaugurada com uma festiva reunião de propaganda no próximo sábado.

\section{Liga Operária do Belenzinho}

Em uma reunião bastante concorrida, ficou constituída, no meio do mês passado, esta Liga, que está tratando de montar a sua sede no bairro, onde instalará uma sala de leitura e realizará sessões de propaganda social.

\section{No Cambuci e na Lapa}

Além do comício realizado na praça pública, celebrou-se num salão do bairro Cambuci uma reunião a fim de serem lançadas as bases do acordo aprovadas anteriormente e já publicadas.

Na Lapa deve ser realizada uma reunião amanhã à noite, esperando-se que ela seja muito concorrida, pois numeroso é o operariado naquele recanto industrial da cidade.

\section{Em S. Caetano}

Neste subúrbio da Inglesa foi constituída uma sociedade de trabalhadores metalúrgicos, que já tem realizado algumas reuniões de propaganda. (VILLAR, 1917a, p. 3)

Podemos observar que o enunciador reitera e destaca a grande frequência com que ocorriam as reuniões das ligas operárias e de associações proletárias afins, assim como repete 
e ressalta a considerável afluência de membros nessas ocasiões: "Numerosas reuniões foram realizadas", "contando com um bom número de associados", "Em uma reunião bastante concorrida", "esperando-se que ela seja muito concorrida, pois numeroso é o operariado" (VILLAR, 1917a, p. 3). O léxico é aí decisivo, mas também a orientação argumentativa conduz ao efeito de sucesso dos eventos: se as reuniões anteriores foram numerosas e bemsucedidas e se o movimento de organização e de adesão à organização operária é crescente, os próximos eventos necessariamente serão exitosos. Deve menos nos interessar a condição real, imaginária e/ou simulada desse sucesso do que a compreensão de fatores da história que impõem ao sujeito a necessidade de sua reiteração e de seu destaque: os movimentos sociais, em particular, os marginalizados afastam os déficits e estigmas que lhes foram imputados, para reforçar as convicções de seus membros e simpatizantes, para arregimentar novos partidários e para enfraquecer indiferenças e objeções dos que não lhes são afeiçoados.

Nas duas notas seguintes são noticiadas conquistas já obtidas pelos movimentos grevistas e pela organização operária. Assim, se afirma a força de um movimento que já obtivera expressivos resultados em suas lutas. Do fragmento se depreende ainda o emprego de dois recursos para a produção da ideia de efervescência política: a ocorrência simultânea de vários acontecimentos, como vemos em "Além do comício realizado na praça pública, celebrou-se num salão do bairro Cambuci uma reunião"; e o ambiente eufórico que os constituía, tal como em "uma festiva reunião de propaganda". Não se trata aqui de pôr em xeque ou de atestar a realidade desse clima de ebulição e das conquistas anunciadas, mas de entender as condições histórias que condicionam o que pode e deve ser dito pelos sujeitos de uma sociedade, as maneiras pelas quais esses dizeres podem e devem ser formulados e as esferas sociais e os meios pelos quais as coisas ditas podem e devem emergir e circular.

Verificamos ainda ali o efeito de um discreto anúncio: "sua sede no bairro, onde instalará uma sala de leitura e realizará sessões de propaganda social"3. Tanto ou mais do que o aviso sobre a sede vale a declaração do que se fará em suas dependências: leitura e propaganda social. A indignação ou a ênfase de outros textos cede aqui a certo tom anódino, mas, nem por isso, torna o recado dado menos importante. Observamos que o enunciador responde pelo que diz e por sua maneira de dizer ao estigma do iletrismo atribuído aos trabalhadores. Onde o pensamento conservador tende a só ver a violência e a rudeza do corpo e da voz do operário, se afirma sua capacidade no trato com a língua e, ainda mais, em sua modalidade escrita. Afirmá-lo de modo discreto, sob a forma de um anúncio, também concorre para afastar os traços de agressividade frequentemente imputados aos operários e da radicalidade não raras vezes infligida aos militantes.

Examinemos, agora, um texto de A Plebe, intitulado "Pigmeus e gigantes", no qual a fala e a postura burguesas são opostas às proletárias:

Por ocasião da série de sermões realizados na matriz do Braz, pelo revmo. San Detole, tive o ensejo de assistir a uma palestra entre ele e alguns camaradas que, em comissão, foram convidá-lo para uma controvérsia.

O ilustre prelado, depois de justificar a sua negativa, entreteve-se em fazer alarde da sua alta posição social, de privilegiado, de príncipe eclesiástico, comparando-a com a humilde condição dos propagandistas dos partidos avançados.

Discorria, com ênfase e sensualidade, detalhando a sua opulenta vida de apóstolo do Cristianismo, esquecendo-se da humildade de origem dessa seita, que, segundo a mitologia, teve por chefe um plebeu, um boêmio, que passou a vida entre os maltrapilhos.

"Na Itália - dizia o discípulo de Loyola - enquanto os delegados das câmaras de trabalho e dos grupos subversivos que viajavam nas estradas de ferro ocupavam os carros da $3^{\text {a }}$. classe, eu e minha comitiva ocupávamos os da $1^{\text {a }}$. Enquanto eles se instalavam em hospedarias da escória social, nós éramos conduzidos em automóvel aos hotéis de luxo." "Como veem, acrescentava, passando a mão alva sobre o rosto efeminado, apesar da minha idade madura, ainda conservo o vigor da juventude...” (...)

\footnotetext{
${ }^{3}$ Todos os excertos acima foram igualmente extraídos de Villar (1917a, p. 3).
} 
Os privilegiados, os que desempenham funções políticas ou religiosas elevadas e bem remuneradas, podem, por um momento, julgar-se superiores, grandes, colocados nos cumes das montanhas, no pináculo da glória, mas estudando, analisando bem a sua situação chega-se à conclusão de que ainda não saíram do vale, que a sua personalidade é supinamente mesquinha.

(...)

Na praça pública instalamos a tribuna popular, de onde lançamos, desassombradamente, sobre a horda parasitária e tirânica os nossos anátemas, fulminando-a com nossa crítica despiedada e com os potentes raios de nossas ideias. (SOARES, 1917, p. 3-4)

A partir do que teria sido uma experiência vivida, visto que o enunciador declara ter assistido à "palestra" entre o revmo. San Detole e alguns de seus camaradas, ele passa a comentar na sequência de seu texto a cena que havia testemunhado. Desde a exposição do contraste entre o convite feito pelos últimos ao primeiro e a recusa do religioso, o enunciador instaura várias oposições que atravessam praticamente toda extensão de seu artigo: de um lado, estão um único indivíduo, o "revmo. San Detole", suas declarações e seu perfil; de outro, uma coletividade "em comissão", os "camaradas", que são "propagandistas dos partidos avançados". No que respeita ao que teria sido dito e aos modos de dizer dos "camaradas", com exceção do próprio convite, retratado sob a forma de um distante discurso indireto, é preciso reconhecer que não lhes é dedicada uma única palavra de forma manifesta e específica. Os propagandistas, seres falantes por excelência, ali praticamente não saem do silêncio.

Por outro lado, se fala muito e detalhadamente do que diz e das maneiras de dizer do "ilustre prelado". Trata-se de um falastrão, pois, além de já ter feito uma "série de sermões" e de "justificar a sua negativa" ao convite que lhe fora feito, ele faz "alarde da sua alta posição social" e a compara com a "humilde condição dos propagandistas". O sacerdote peca por atos e omissões, por falta e excessos. Fala de modo exagerado, lascivo e minucioso daquilo que não apenas deveria ser calado, mas que, antes, não deveria nem sequer ser cogitado: "Discorria, com ênfase e sensualidade, detalhando a sua opulenta vida de apóstolo do Cristianismo". E silencia uma das virtudes maiores de sua doutrina, a condição popular de seu líder e daqueles que ele frequentava: "esquecendo-se da humildade de origem dessa seita, que teve por chefe um plebeu, um boêmio, que passou a vida entre os maltrapilhos" (SOARES, 1917, p. 3). Ademais, a reprodução da fala de San Detole em discurso direto põe em sua própria boca seu apego à ostentação e à vaidade. Já o parágrafo seguinte do texto parafraseia seu título: os que se tomam por "gigantes" não passam de "pigmeus":

Os privilegiados podem, por um momento, julgar-se superiores, colocados nos cumes das montanhas, no pináculo da glória, mas estudando, analisando bem a sua situação chega-se à conclusão de que ainda não saíram do vale, que a sua personalidade é supinamente mesquinha. (SOARES, 1917, p. 3)

É mediante a opção enunciativa pelo "nós" que se estabelece o escopo das coisas ditas e são descritas as propriedades de seu modo de dizer:

$\mathrm{Na}$ praça pública instalamos a tribuna popular, de onde lançamos, desassombradamente, sobre a horda parasitária e tirânica os nossos anátemas, fulminando-a com nossa crítica despiedada e com os potentes raios de nossas ideias. (SOARES, 1917, p. 4)

Não se poderia ali instalar uma tribuna qualquer, mas uma que fosse efetivamente "popular"; nela, não se trataria de dizer algo, mas de execrar abertamente uma facção criminosa. A forma da expressão é enérgica ("anátemas", "fulminando", "crítica despiedada" e "potentes raios"), porque o inimigo é parasita, porque o enunciador conhece uma verdade 
profunda e ainda porque sua enunciação deve ser proporcional ao tamanho dos danos causados ao povo pelas opressões capitalistas.

Na segunda edição de $A$ Plebe, há um texto em que se noticia a realização de um comício. Seu enunciador apresenta a causa e a finalidade do evento, a entidade que o organizou e o dia, o horário e o local em que ele ocorreu. Menciona ainda seu sucesso de público e descreve certos aspectos da fala pública que ali se praticou. Fora uma mostra da solidariedade e da indignação de operários paulistas para com seus colegas cariocas, em decorrência de uma tragédia recentemente acontecida e que havia sido noticiada na edição anterior de $A$ Plebe, com os seguintes títulos e lead: "Os crimes da burguesia"; "O horroroso desastre do Rio" e "Numerosos trabalhadores sacrificados em holocausto à ganância dos argentários". Como de costume, em um texto atravessado pela explícita crítica social, esta sequência informa mais precisamente o leitor do que se havia passado: "Com o desabamento de um grande prédio em construção, ficaram soterradas algumas dezenas de operários, surpreendidos na insana labuta para o magro ganha pão" (VILLAR, 1917b, p. 2). Essa era razão por que se realizara o comício no Braz, descrito nos seguintes termos na edição daquele 16 de junho de 1917:

O horrível desastre do Rio

Comício de protesto no Braz

Querendo secundar aqui a manifestação de protesto do proletariado carioca contra a conduta criminosa da burguesia que, com a sua insaciável ganância, provoca os desastres horríveis, como o do Rio, a Liga Operária da Mooca promoveu um comício no domingo, realizando-se ele à noite, no largo da Concórdia, com numerosa concorrência.

Vários companheiros fizeram uso da palavra estigmatizando a ação infame dos argentários e concitando os trabalhadores à luta ativa e decidida contra os ladrões e tiranos do povo. (VILLAR, 1917b, p. 2)

Ao fundamental apoio ao protesto dos operários do Estado vizinho e à necessária denúncia da postura burguesa "criminosa", marcada por "sua insaciável ganância" e pelos "desastres horríveis" que ela produz, soma-se algo que pode parecer uma mera informação factual: "um comício no domingo, realizando-se ele à noite". Há aí, no entanto, o anúncio de que é, sobretudo, no tempo de descanso que se constituem os sonhos do povo. Já na apresentação de seu livro intitulado A noite dos proletários, Jacques Rancière afirmava que "a transformação do mundo começa no momento em que os trabalhadores normais deveriam desfrutar do sono tranquilo daqueles que têm um trabalho que não os obriga a pensar". Foi esse o ensejo para que Rancière constituísse uma

\footnotetext{
história dessas noites subtraídas à sequência de trabalho e descanso; interrupção imperceptível, aparentemente inofensiva, do curso natural das coisas, na qual se prepara, se sonha, se vive já o impossível: a suspensão da ancestral hierarquia que subordina os que se dedicam ao trabalho com as próprias mãos aos que foram contemplados com o privilégio do pensamento. (RANCIËRE, 1988, p. 9)
}

Nessas noites, as jornadas de trabalho se prolongam para que os operários ouçam "a palavra dos apóstolos ou a lição dos instrutores do povo", para que, assim, possam "aprender, sonhar, discutir ou escrever" 4 .

Aqui novamente o enunciador ressalta a grande afluência de público no comício organizado pela Liga Operária da Mooca: "com numerosa concorrência". Ora, já dissemos que as formas de um enunciado não podem ser ignoradas. Por isso, não podemos passar ao largo das referências ao dia e horário do comício, bem como do destaque dispensado ao número de seus frequentadores. Além disso, de tudo aquilo foi dito nessa curta nota " $O$

\footnotetext{
${ }^{4}$ Rancière (1988, p. 10).
} 
horrível desastre do Rio" / "Comício de protesto no Braz", o que mais nos desperta a atenção é seu último parágrafo, na medida em que é ali que se encontra uma referência direta à fala pública popular. São várias as marcas contidas nessa formulação às quais devemos dar relevo. Para fazê-lo, vamos nos valer da construção de algumas paráfrases, no intuito de indicar a especificidade das coisas ditas e de seus modos de dizer.

Comecemos pelo sintagma "Vários companheiros". O lugar ocupado por "Vários" poderia ter sido preenchido por "Poucos", por "Alguns", por "Nobres" etc., ao passo que "companheiros" poderia ser substituído por "senhores", por "militantes", por "correligionários" etc. Vejamos, em seguida, por que esse sujeito se agrega muito bem ao predicado da oração, "fizeram o uso da palavra". Este último segmento poderia ter sido formulado dos seguintes modos: "discursaram", "deram provas de sua eloquência" ou "embeveceram a massa com sua oratória", entre outras possibilidades. A forma escolhida, em detrimento das tantas possíveis, produz o efeito de que ali os sujeitos e os ideais são igualitários, sóbrios e despojados. Naquele contexto, não são "poucos", mas "vários" os que podem se expressar publicamente; eles não são nem superiores nem inferiores ao enunciador da nota de $A$ Plebe, nem lhe são distantes, porque o acompanham de perto e no mesmo nível rumo à mesma direção política. Não fazem belas declarações, mas apenas "uso da palavra", porque menos lhes interessariam o brilho da eloquência e a glória conquistada com um performático desempenho do que a simplicidade de sua intervenção decorrente da verdade da causa a serviço da qual combatem. A ação em nome dessa causa mobiliza duas frentes de atuação, uma que compreende o ataque ao inimigo e outra que corresponde ao agenciamento dos companheiros para combater o bom combate.

No comício de protesto no Braz, não haveria, portanto, alguns poucos, ilustres e eloquentes oradores que brindariam um auditório encantado com seu distinto talento oratório, porque tampouco haveria longos e solenes pronunciamentos, mas, como dissemos, somente o simples uso da palavra. Lá "vários companheiros" o fazem, tanto para denunciar "a ação infame dos argentários" quanto para concitar "os trabalhadores à luta ativa e decidida contra os ladrões e tiranos do povo". Não se trataria, então, de apenas conhecer a ação inimiga e de revelá-la, mas de escancarar suas perversidades, isto é, de apontar abertamente para as iniquidades que produz e das quais as elites tiram proveito. Além disso, não se estaria diante de uma ação qualquer, visto que ela é "infame"; assim como não é produzida por quaisquer uns, mas por "argentários". O artigo definido que precede "ação" constrói um efeito de que a referida ação é algo real e bastante conhecido, enquanto o adjetivo "infame" e o adjunto "dos argentários" que seguem aquele substantivo produzem os sentidos de uma ação vil praticada por sujeitos gananciosos, a quem só o dinheiro interessa. Os argentários são retomados e parafraseados no próprio parágrafo por "os ladrões e tiranos do povo"; ou seja, além de visarem aos ganhos a qualquer custo, eles são perversos, porque roubam do povo aquilo que este último produziu e ainda o oprimem por repressão e astúcia. É por essa razão que os companheiros interpelavam seus congêneres trabalhadores a lutar contra esses usurpadores. Ao invés da alienação, a consciência da exploração sofrida; ao invés da inércia, a luta; e ao invés de uma luta sem maior empenho, uma que fosse "ativa e decidida".

Ainda nessa edição, encontramos, entre outros, o seguinte texto:

Liga Operária da Mooca

Esta associação vai em franca prosperidade, pois durante estes últimos dias recebeu a adesão de mais de 600 operários de ambos os sexos.

Este fato demonstra que a classe operária se preocupa das suas reivindicações e não espera senão de seus próprios esforços o seu direito à subsistência e à liberdade.

A sua sede acha-se instalada em um amplo local, à rua da Mooca, 292 B, onde sempre se encontram reunidos numerosos operários, que discutem com interesse e calor as questões operárias e sociais. (VILLAR, 1917b, p. 4) 
A trajetória ascendente de êxitos quanto à adesão de um crescente e considerável número de filiações. Sua enunciação em terceira pessoa indica, ao mesmo tempo, i) um modo de corresponder ao padrão de escrita da imprensa, ii) um efeito de relativo distanciamento entre quem diz e a coisa dita e iii) certa credibilidade do que se diz. Assim, o enunciador menciona não apenas o que seria um grande número de operários aderentes à Liga, mas também sua pertença ao sexo masculino e ao feminino: "mais de 600 operários de ambos os sexos". O fato de que os morfemas "o" e "s" já marcassem um masculino "neutro" plural de "operários", visto que ele poderia já compreender mulheres operárias em seu conjunto, não foi suficiente ao enunciador para que ele pudesse instaurar, como julgara ser necessário, uma referência a estas últimas. Seu modo de fazê-lo é bem particular, porque se trata de optar por uma alusão mais marcada do que a forma que se limitaria ao neutro plural. Além disso, há ali ainda a reiteração do princípio anarquista segundo o qual deve ser o próprio povo oprimido o agente de sua emancipação: "a classe operária se preocupa das suas reivindicações e não espera senão de seus próprios esforços o seu direito à subsistência e à liberdade" (VILLAR, 1917b, p. 4).

Destacamos, por último, os dados, informações e qualificações contidos no último período dessa nota ora examinada. A sede não é um lugar qualquer nem se encontra em endereço desconhecido; seria, antes, "um amplo local", localizado precisamente "à rua da Mooca, 292B". Tampouco corresponderia a um espaço ocioso ou de quaisquer atividades, porque é, antes, "onde sempre se encontram reunidos numerosos operários". A atividade é, portanto, constante, assim como é grande o fluxo de trabalhadores que o frequentam. Se o lugar é amplo e precisamente localizado e se sua frequentação é contínua e numerosa, lá os operários não se reúnem para frivolidades, mas para discutir importantes "questões operárias e sociais". Suas discussões são marcadas por índices do compromisso com as causas trabalhadoras, dado que se processam com "interesse" nas escutas e com "calor" nas falas que ali ocorrem. Contrasta com esse operariado assim engajado uma "massa imbecilizada". $\mathrm{Na}$ mesma edição de A Plebe, se descreve uma cerimônia religiosa, na qual "a rançosa gente das sacristias" induzia a massa a cantar "Queremos Deus como nosso pai / Queremos Deus como nosso rei". Enquanto aquela gente dava "uma demonstração de sua deplorável subserviência" exatamente em frente à redação de A Plebe, a equipe do jornal estendeu um "rubro pendão subversivo, desfraldado ao vento" para manifestar "o protesto da geração nova que trabalha para conduzir o povo à sua emancipação". Como vemos, aqui não se fala em indução, mas em condução do povo; esta, por sua vez, não o levaria ao servilismo, mas à sua emancipação.

\section{CONSIDERAÇÕES FINAIS}

Apesar de sua brevidade, o exame dos textos desse importante veículo da imprensa operária nos proporcionou a observação do que ali se diz distintamente das práticas burguesas de fala pública e de suas congêneres proletárias e ainda das diversas formas pelas quais se formulam esses dizeres. Das primeiras, vimos a "tagarelice" de Rui Barbosa e a soberba de San Detole. O texto que trata deste último relata a "palestra" entre ele, o "ilustre prelado", e "alguns camaradas" operários, e descreve minuciosamente o que diz e os modos de dizer do religioso, além de reproduzir sua fala, sob a forma de discurso direto, ainda que seja para mais bem desqualificá-la. Em contrapartida, não há referência ao que dizem e as maneiras de dizer dos "companheiros". Noutros textos, especificamente dedicados aos movimentos e organizações operárias, encontramos algumas outras referências às coisas ditas e aos modos de dizer que seriam próprios das falas púbicas populares ${ }^{5}$.

\footnotetext{
${ }^{5}$ Para mais bem conhecer práticas e representações da fala pública, ver Courtine; Piovezani (2015).
} 
O fato de haver uma relativa discrição e alguma economia no que se fala em A Plebe dos desempenhos oratórios proletários e de suas circunstâncias de fala pública não significa que eles tenham sido completamente negligenciados. Vimos que há índices suficientes para que pudéssemos depreender certas propriedades do que disseram os enunciadores do jornal anarquista e de como formularam seus enunciados nas representações discursivas dos "usos da palavra" nas assembleias operárias. Talvez, antes e em conjunto com esse parcial silêncio sobre aquelas falas públicas feitas pelo povo ou por seus porta-vozes e sobre os regimes de escuta que elas ensejavam, resida aí mais uma tentativa de se distinguir da pompa e do protocolo que se identifica na oratória burguesa. Isso, contudo, não impediu que reconhecêssemos, principalmente, nos textos editoriais de mais longo fôlego, certos traços de uma aristocrática retórica tradicional. Se as contradições jamais estão alheias da história, em geral, também não poderiam ser completamente estranhas aos discursos sobre as práticas populares de linguagem. Sua identificação e sua análise podem não ser suficientes, mas são bastante necessárias à luta contra a conservação dos dizeres que continuam a detratar as falas e a escuta de empobrecidos e marginalizados do povo brasileiro.

\section{Referências}

COURTINE, Jean-Jacques; PIOVEZANI, Carlos. (Org.) História da fala pública: uma arqueologia dos poderes do discurso. Petrópolis, Vozes, 2015.

FERREIRA, Maria Nazaré. A Imprensa operária no Brasil. Petrópolis: Vozes, 1978.

GIANNOTTI, Vito. História das lutas dos trabalhadores no Brasil. Rio de Janeiro: Mauad X, 2007.

LEUENROTH, Edgard. Ao que viemos. Rumo à revolução social. A Plebe, São Paulo, 09 jun. 1917, p. 1.

LOPREATO, Christina Roquette. O espírito da revolta: a greve geral anarquista de 1917. São Paulo: Annablume/Fapesp, 2000.

RANCIÈRE, Jacques. A noite dos proletários: arquivos do sonho operário. São Paulo:

Companhia das Letras, 1988.

SOARES, Primitivo (codinome de Roberto Feijó). Pigmeus e gigantes. A Plebe, São Paulo, 09 jun. 1917, p. 3-4.

VILLAR, Cecílio. Acção obreira. O operariado de São Paulo parece despertar para a luta. A Plebe, São Paulo, 09 jun. 1917a, p. 3.

VILLAR, Cecílio. Acção obreira. Sucedem-se as greves. A Plebe, São Paulo, 16 jun. 1917, p. $2-4$.

Recebido em: 20/02/2019

Aceito em: 20/04/2019

Publicado em: Junho de 2019 